to prevent the accumulator being run down completely. Nowadays, ammeters and voltmeters of precision are available at low prices for laboratory work. This is due to the great demand for them by the wireless industry.

When electricians agreed to make alternating current supply the standard, many laboratories found themselves in considerable difficulties, as a steady direct current is needed for many fundamental experiments. Luckily, the copper-oxide rectifier developed by the Westinghouse Company in the United States 'converts' the alternating current into direct current most satisfactorily. These efficient and apparently everlasting little pieces of apparatus have saved physical laboratories large sums of money and have proved of immense help. The copper-oxide rectifier when exposed to light is found to generate an electric current. It is therefore possible to use it in photometry and for measuring the density of photographic blackening.

Prof. Oliphant pointed out how the work of Cockcroft, Lawrence and Kapitza has revolutionized the apparatus required for a physical laboratory. With the help of the Metropolitan-Vickers Electrical Co., Ltd., a 50-cycle 2,000 kw. A.c. generator has been constructed the nominal rating of which is $2,000 \mathrm{kw}$., but when short-circuited for half a cycle develops a power of $55,000 \mathrm{kw}$. Magnetic fields were generated of considerable volume under a magnetic force of 300,000 gauss. Dr. T. E. Allibone's valuable work on the problem of applying high electric potentials to evacuate insulating vessels is of great importance. Before he left the Cavendish Laboratory he had succeeded in producing considerable beams of artificial $\beta$-rays.

Dr. C. R. Burch, of Metropolitan-Vickers, found that it is possible to produce by vacuum distillation of mineral oils, residual oils with very low vapour pressure. These oils can be distilled unchanged in a vacuum of a fraction of a millimetre. The apparatus of Cockcroft and Walton was an unqualified success and with it they showed for the first time that accelerated particles of hydrogen can penetrate the nucleus of certain atoms and produce profound changes in them. This and the discovery of the neutron stimulated research into these problems all over the world.

At the same time that Cockeroft and Walton were developing the high-voltage method for accelerating particles, Prof. E. C. Lawrence of Berkeley, California, was experimenting with indirect methods which do not require large voltages. $\mathrm{He}$ was successful in developing the 'cyclotron', by means of which he accelerated particles to energies corresponding with nine million volts. The cyclotron has proved of immense utility to nuclear research. Unfortunately it is very expensive. The magnets of the cyclotrons at Liverpool and Cambridge weigh 50 tons each, of which seven tons is copper, and they produce a field of 19,000 gauss over a gap $90 \mathrm{~cm}$. in diameter.

The new branches of physies are by far the most fundamental of any as they touch the ultimate constitution of matter itself. They can only be attacked successfully by very highly skilled teams of workers, as the number of pieces of intricate apparatus which has to function simultaneously is very large. New effects are being continually observed, and it is necessary to explain them and correlate them with existing knowledge.

Rutherford and Geiger were able to detect and count for the first time the number of $\alpha$-particles emitted by a gram of radium, but the method has several defects and is exceedingly difficult to apply. The method now used is to amplify the current produced in a small ionization chamber by the pulse of ions due to each $\alpha$-particle. This is heard as a loud click in a speaker attached to the amplifier.

Prof. Oliphant concluded by giving a quotation from Bacon, frequently used by Rutherford : "Human knowledge and human power are coextensive; for ignorance of causes prevents us from producing effects. Nature can only be ruled by being obeyed; for the causes which theory discovers give the rules which practice applies."

\title{
Radio Exhibition, Olympia
}

$\mathrm{T}$ HE annual exhibition of wireless apparatus organized by the Radio Manufacturers' Association was held at Olympia on August 24 until September 3, and it was notable for such features as the replacement of the B.B.C. Radio Theatre by a glass-walled television studio in operation, the first large display of television receivers in actual operation on exhibitors' stands, and the complete demonstration of sound broadcasting receivers for the first time. On previous occasions the stands were supplied inside the exhibition with audio-frequency programme current, so that no demonstration of the radio frequency portion of receivers could be given. This year, arrangements were made for all stands to be supplied with radio frequency signals so that the various receivers could be demonstrated as a whole.

On the technical side, sound broadcasting receivers appear to have settled down to fairly standard types of design, and with the steady improvement of detail which has resulted in methods of lay-out and manufacture during recent years, the modern receiver is very efficient and supplies the needs of the majority of listeners. The chief novel feature among this year's sets is the incorporation of some form of automatic tuning, by means of which a certain number of broadcasting stations can be selected at will by operating switches on the front of the receiver. To what extent this feature was really required by the listener time will tell, but it would appear to be consistent with the demands of the age and to have advantages comparable with those of the automatic telephone and the pre-selector gear on motor-cars. The automatically tuned receiver is provided with a series of about six push-buttons in addition to the usual on-and-off switch; by pressing one of these buttons, the receiver is automatically adjusted to receive the programme from a certain station. In some cases the actual stations made available to the press-button control can be altered by carrying out certain more or less simple adjustments on the receiver. The manner of achieving this automatic tuning varies among the manufacturers and has called forth a considerable amount of mechanical ingenuity in some cases. The methods vary from the switching in of one of a series of fixed condensers across each tuned circuit of the receiver, to the use 
of a motor driving the main ganged variable condenser in conjunction with an electrical method of obtaining accurate synchronism with the incoming signals. In all cases, the purchaser is assured that the addition of this automatic device in no way reduces the efficiency of the receiver as a whole or affects the ability to operate it manually.

On the television side, the large display of receivers in operation on the various stands demonstrated admirably that this phase of the art is now on a commercial production basis, and made the visitor prone to forget that the potential market at present is limited to those who reside within about thirty miles of Alexandra Palace. It is well known that reception of television has been successfully accom. plished at much greater distances, but the above represents the reliable service range at present. A determined effort has been made by manufacturers to reduce the cost of television receivers to the minimum; and by the use of smaller cathode ray tubes, giving good results with a picture size of about $4 \frac{3}{4}$ in. by 4 in., complete sound and vision receivers are now available at from a little more than twenty pounds. At least one manufacturer has realized also that many listeners are already ade. quately provided with a normal sound broadcasting receiver, for there is now available a set for television reception only, but including the sound programme appropriate thereto. One of these sets gives a satisfactory picture of size $7 \frac{1}{2}$ in. by 6 in., and the price shows a saving of one third over that of a similar model giving all-wave broadcast reception in addition to the television. In many cases the previous version of the domestic television receiver giving a larger picture of size $10 \mathrm{in.} \mathrm{by} 8 \mathrm{in}$. has been retained, but it is naturally more expensive. Some firms provide more elaborate equipment which, by projection on to a small cinema screen, gives a picture of the order of $24 \mathrm{in}$. by $20 \mathrm{in}$. in size, and this provides comfortable viewing for a score or so of persons. In some cases this large picture is obtained by projection from a comparatively small image produced on the screen of a cathode ray tube of $3 \mathrm{in}$. or 4 in. diameter. In one case, however, the scanning was carried out mechanically by special forms of mirror drum, and the satisfactory demonstration given testified to the success which has been achieved in the development of the high- and low-speed motordriven scanners employed in this system.

The remainder of the exhibition was devoted largely to the miscellaneous components and accessories utilized by the radio receiver industry. Loudspeakers and public-address equipment, test and service apparatus, special condensers, switches and other components were displayed in all their variety. The Post Office exhibit showed the various methods and devices adopted to mitigate the interference nuisance, and some firms displayed apparatus and devices for measuring and reducing this interference. Lastly, and by no means least, that most important component, the thermionic valve, was shown still to be making steady progress in the direction of increased efficiency in meeting the varied demands now made upon it. While it is perhaps regrettable that this development has resulted in an increase in the number of types of valves and also in the valve bases, some consolation is perhaps to be drawn from the fact that reductions in price of the order of 20 per cent on many types were announced by several manufacturers just prior to the opening of the exhibition.

\section{Science News a Century Ago}

\section{Ascent of Mont Blanc by a Lady}

"A French lady named Dangeville ascended to the summit of Mont Blane on the 4th inst [Septem. ber 1838]. She quitted the valley of Chamonix on the 3rd, at an early hour in the morning, slept at the Grand Mulets, and reached her perilous destination at 12 o'clock on the 4th. She remained on the summit of the mountain for about an hour, wrote some notes, and drank a health to the Count de Paris. The guides by whom she was accompanied spoke in the highest terms of her courage, perseverance and presence of mind. Previous to this successful trip, the feat had been accomplished by only one female, a peasant of Chamonix, who, on reaching the grand plateau became exhausted with fatigue and was carried by force to the summit. Mademoiselle Dangeville on her return to the Chamonix on the morning of the 5th inst, was received with the utmost enthusiasm by the inhabitants, who proceeded to meet her, and fired salutes of cannon in honour of her exploit." (Annual Register, 1838.)

\section{Lyell at the Athenæum}

Writing on September 8, 1838, to Darwin, Lyell said : "I am very glad to hear you like the Athenæum. I used to make one mistake when first I went there. When anxious to push on with my book, after a 'two hours' spell', I went there by way of a lounge and instead of that, worked my head very hard, being excited by meeting with clever people, who would often talk to me, very much to my profit, on the very subject on which I was writing, or I fell in with a Review or Magazine relating to geology. Now this was all very well, but I used to forget that this ought to count for work, although nothing had been written, and that I ought consequently to give up my second 'two hours' spell. . . . As your eyes are strong, you can afford to read the light articles and newspaper gossip, which I could never indulge in much with impunity."

\section{Colours of Thin Plates}

THE Mechanic's Magazine of September 8, 1838, contained a contribution from Charles Tomlinson (1808-1897) on "Experiments and Observations on the Colours of Thin Plates". Prefacing his remarks by a note on the various modes of obtaining Newton's rings and the colours of thin plates which were generally known, he offered to scientific men some new facts. Some of his experiments had been made with spirit of turpentine and balsam of Peru. "When a drop of balsam of Peru," he wrote, "is allowed to fall upon the surface of water we instantly get a magnificent display of coloured rings: on applying vapour of ether, ammonia, etc., to any part of the film, its thickness is instantly reduced, so that the colour belonging to one order of Newton's rings is instantly exchanged for the colour of one of the series above it.

"A magnet seems also to have an action upon the film, the North pole tending to repel it, and the South pole to attract it."

Tomlinson, who was elected F.R.S. in 1872, made important discoveries concerning surface tension in liquids. 